\title{
Oral hygiene status of depressed patients
}

\author{
Putri Permatasari ${ }^{1}$, Gilang Yubiliana ${ }^{1 *}$, Aulia Iskandarsyah² \\ ${ }^{1}$ Department of Dental Public Health, Faculty of Dentistry Universitas Padjadjaran, Indonesia \\ ${ }^{2}$ Department of Clinical Psychology, Faculty of Psychology Universitas Padjadjaran, Indonesia
}

\begin{abstract}
Introduction: Oral hygiene is one of the most critical factor in maintaining oral health. Depression symptoms may affect an individual's oral health due to poor health behaviour, making depressed individuals prone to oral diseases such as caries and periodontal diseases. This study was aimed to obtain the oral hygiene status overview of depressed patients in West Java Psychiatric Hospital. Methods: This study was an observational descriptive with a cross-sectional approach to depressed patients (F.32 ICD Code). The measuring instrument used was Oral Hygiene Index-Simplified (OHI-S). Based on $\mathrm{OHI}-\mathrm{S}$, oral hygiene can be assessed into poor within 3.0 - 6.0 score point, fair within 1.3-3.0 score point, or good within 0.0 - 1.2 score point. Results: There were 30 respondents recruited using a purposive sampling method. Based on the plaque index, 1 respondent (3\%) fell into good category, 23 respondents (77\%) fell into the fair category, and 6 respondents (20\%) fell into poor category. Based on the calculus index, 7 respondents (23\%) fell into good category, 10 respondents $(60 \%)$ fell into the fair category, and 5 respondents $(17 \%)$ fell into poor category. Based on OHI-S, 2 respondents (7\%) fell into the good category, 18 respondents $(60 \%)$ fell into the fair category, and 10 respondents (33\%) fell into poor category. Conclusion: Oral hygiene in-dex of depressed patients was categorised as fair.
\end{abstract}

Keywords: Depression, Oral Hygiene Index-Simplified, OHI-S, oral hygiene status.

p-ISSN: 1979-0201; e-ISSN: 2549-6212; Available from: http://jurnal.unpad.ac.id/pjd/article/view/21165

DOI: 10.24198/pid.vol32no1.21165

Submission: Jun 26, 2019; Accepted: Mar 27, 2020; Published online: Mar 31, 2020

\section{INTRODUCTION}

The World Health Organization (WHO) defines mental health as a state of well-being in which every person realizes their potential, able to cope with normal stresses, able to work productively, and able to contribute to their community. ${ }^{1}$ Mental disorder is a term used to describe a state of mental health that may affect emotions and cognitive functions. ${ }^{2}$ Mental disorders are one of the most prevalent disorders in the world and nowadays mental health is a major concern of public health. ${ }^{3}$ The most common mental disorders are depression, bipolar, schizophrenia, dementia, intellectual disabilities, and developmental disorder including autism. ${ }^{4}$

Depression has been linked with toothache, gum bleeding, and tooth loss. ${ }^{2}$ These patients are prone to a greater number of risk factors for oral and dental diseases than the general population 
due to secondary effects of medication, lack of self-care, difficulty to access health services, poor attitude towards healthcare providers, and lack of cooperation with dental treatments. ${ }^{5}$

Depression symptoms may affect an individual's oral health due to poor oral health behavior such as poor oral hygiene maintenance, higher carbohydrate intake, poor perception of oral health self-needs, length of psychotropic treatment, and difficulty to access dental care. ${ }^{4}$ Moreover, depressed individuals are often less motivated to maintain their oral hygiene thereby causing poor oral health and oral diseases such as dental caries and periodontal diseases. ${ }^{4}$

The World Health Organization (WHO) defines oral health as a state free from mouth and facial pain, oral and throat cancer, oral infection and sores, periodontal diseases, and disorders which limit an individual's ability in biting, chewing, smiling, speaking, and psychosocial wellbeing. ${ }^{6}$ Optimal oral hygiene behavior is required to maintain good oral health. ${ }^{7}$ Oral hygiene is defined as an individual's oral state in which free from debris, plaque, and calculus. ${ }^{8}$ An individual's oral hygiene status can be assessed using Oral Hygiene Index Simplified which sums plaque index simplified and calculus index simplified. ${ }^{9}$

Based on these preceding theories, the author was interested to study the oral hygiene status of depressed patients in West Java Psychiatric Hospital. This study was aimed to obtain the oral hygiene status overview of depressed patients in West Java Psychiatric Hospital.

\section{METHODS}

This study was an observational descriptive with a cross-sectional approach to depressed patients (F.32 ICD-10 Code) in West Java Psychiatric Hospital using $\mathrm{OHI}-\mathrm{S}$ as measuring instrument. ICD is an abbreviation of International Classification of Diseases, and F.32 is a code to classify depressive episode in general whether its mild, moderate, or severe depressive episodes. This This study was held between February until March 2019. The population of this study was West Java Psychiatric Hospital patients and 30 samples were taken using purposive sampling method based on inclusive and exclusive criteria. Inclusive criteria were depressed patients based on hospital's medical record (F.32 ICD Code), patients given psychotropic treatments, and patients with fully erupted observed teeth, whereas exclusive criteria were patients using orthodontics, patients with intellectual disabilities, blind patients, illiterate patients, and/or deaf patients. Data were collected using $\mathrm{OHI}-\mathrm{S}$ which was a total in Plaque Index and Calculus Index. Both can be categorised into poor within $0.0-0.6$, fair within 0.7 - 1.8, or good within 1.9 - 3.0. Collected data then analyzed using SPSS. Ethical clearance was given from Universitas Padjadjaran Health Research Ethics Commitee with the number of 59/ UN6.KEP/EC/2019.

\section{RESULTS}

This study was conducted to obtain oral hygiene status of depressed patients in West Java Psychiatric Hospital. Table 1 illustrates the general profile of the study samples. Out of 30 patients, 14 were males (47\%) and $16(53 \%)$ were females. A total of $15(50 \%)$ respondents were ranging from 19 to 40 years old, 15 respondents $(50 \%)$ were above 40 .

Table 2 illustrates the mean plaque index, mean calculus index, and mean OHI-S index. The mean plaque index was 1.6 and fell into fair category, and the mean calculus index was 1.2 and fell into fair category. The mean $\mathrm{OHI}-\mathrm{S}$ index was 2.8 and fell into fair category, while based on age grouping, 19 to 40 age group scores 2.6 and fell into fair category, and above 40 age group scores 3.0 and fell into fair category.

Table 1. General profile of study samples

\begin{tabular}{|c|c|c|}
\hline Characteristics & $\mathrm{N}$ & $\%$ \\
\hline \multicolumn{3}{|l|}{ Gender } \\
\hline Male & 14 & 47 \\
\hline Female & 16 & 53 \\
\hline \multicolumn{3}{|l|}{ Age } \\
\hline $19-40$ & 15 & 50 \\
\hline$>40$ & 15 & 50 \\
\hline
\end{tabular}

Table 3 illustrates the more detailed information on each indexes. Based on plaque index, 1 respondent (3\%) fell into good category, 23 respondents $(77 \%)$ fell into fair category, and 6 respondents $(20 \%)$ fell into poor category, and 
based on calculus index, 7 respondents (23\%) fell into good category, 18 respondents $(60 \%)$ fell into fair category, and 5 respondents (17\%) fell into poor category. Based on OHI-S, 2 respondents (7\%)

Table 2. Mean plaque index, calculus index, and OHI-S scores of depressed patients in west java psychiatric hospital

\begin{tabular}{lcc}
\hline \multicolumn{1}{c}{ Indexes } & Mean & Category \\
\hline Plaque Index & 1.6 & Fair \\
Calculus Index & 1.2 & Fair \\
OHI-S & 2.8 & Fair \\
$19-40$ & 2.6 & Fair \\
$>40$ & 3 & Fair \\
\hline
\end{tabular}

fell into good category, 18 respondents $(60 \%)$ fell into fair category, and 10 respondents (33\%) fell into poor category.

\section{DISCUSSION}

Depression is a mood disorder which symptoms may affect how sufferer feels, thinks, and handles daily activities. ${ }^{10}$ Depression not only affect an individual's behavior pattern, but also impair an individual's oral health behavior. ${ }^{4}$ Based on this study, the mean plaque score of depressed

Table 3. Plaque index, calculus index, and ohi-s scores of depressed patients in west java psychiatric hospital

\begin{tabular}{ccc}
\hline Indexes & $\mathrm{N}$ & $\%$ \\
\hline Plaque Index & 1 & 3 \\
Good & 23 & 77 \\
Fair & 6 & 20 \\
Poor & & \\
Calculus Index & 7 & 23 \\
Good & 18 & 60 \\
Fair & 5 & 17 \\
Poor & & \\
OHI-S & 2 & 7 \\
Good & 18 & 60 \\
Fair & 10 & 33 \\
Poor & &
\end{tabular}

patients in West Java Psychiatric Hospital is 2.8 and fell into fair category, the mean calculus score is 1.6 and fell into fair category, and the mean $\mathrm{OHI}-\mathrm{S}$ score is 1.2 and fell into fair category.

The mean plaque index score of West Java Psychiatric Hospital patients was 1.6 which fell into fair category with 1 respondent (3\%) fell into good category, 23 respondents (77\%) fell into fair category, and 6 respondents fell into poor category. These findings were in agreement with Zareen's in 2016 which stated the mean plaque index score of 85 depressed patients was 1.5 and fell into fair category. ${ }^{11}$ These findings were also in agreement with Kumar's in 2014 which stated that depressed patients had higher plaque accumulation compared with control. These findings might be due to reduced motivation and interest, low frequency of tooth brushing, and less effective oral hygiene maintenance. ${ }^{12}$

The mean calculus index score of study samples was 1.2 and fell into fair category with 7 respondents $(23 \%)$ fell into good category, 18 respondents $(60 \%)$ fell into fair category, and 5 respondents $(17 \%)$ fell into poor category. These findings were in agreement with Zareen's in 2016 which stated the mean calculus index score of 85 depressed patients was 1.2 and fell into fair category. ${ }^{11}$ Calculus is mineralized plaque which might be the reason why the mean calculus index scored lower compared to the mean plaque index. ${ }^{13}$ These findings were in agreement with Villa's in 2014 which stated that depression and medications such as antidepressant might cause hyposalivation thereby lowers the flow of saliva and ends in plaque and calculus accumulation. ${ }^{14,15}$

The mean $\mathrm{OHI}-\mathrm{S}$ score was 2.8 and fell into fair category with 2 respondents (7\%) fell into good category, 18 respondents $(60 \%)$ fell into fair category, and 10 respondents (33\%) fell into poor category. These findings were in agreement with Zareen's in 2016 which stated that the mean OHI-S score of 85 depressed patients was 2.7 and fell into fair category. ${ }^{11}$ These findings were also in agreement with Nandaprasad's in 2015 and Persson in 2009. ${ }^{16,17}$ Based on age group, the mean OHI-S score of 19 to 40 year old group was 2.6 and fell into fair category while the mean $\mathrm{OHI}-\mathrm{S}$ score of above 40 year old group was 3.0 and fell into fair category. These findings were in agreement with Azodo's in 2013 and Braimoh's in 2017 which stated that oral hygiene score increases with increasing age. ${ }^{18}$ These findings were also in agreement with Amirah's in 2015 which stated that there was a positive yet weak association between oral hygiene status and age. ${ }^{19}$ 
There might be a few factors which causes poor oral heath among patients with mental disorders such as poor oral hygiene maintenance, higher sugar intake, poor perception of oral health care needs, medications, low frequency of dental visits, lack of interest, low self-esteem, lack of knowledge, and fear of dental treatment. ${ }^{4,20}$ The limitations of this study includes small sample size, descriptive cross-sectional method, and lack of data on several factors affecting oral health such as oral health habits and knowledge. ${ }^{21}$ This study is unable to clarify whether depression might be linked to poor oral hygiene nor it can compare the oral hygiene of depressed patients and nondepressed patients therefore future study should consider these factor for better understandings.

\section{CONCLUSION}

Oral hygiene is one of the most important factor in maintaining oral health. Depression symptoms may affect an individual's oral health due to poor health behavior, making depressed individuals prone to oral diseases such as caries and periodontal diseases. The aim of this study was to obtain the oral hygiene status overview of depressed patients in West Java Psychiatric Hospital. The study was an observational descriptive with a cross-sectional approach to depressed patients (F.32 ICD Code). The measuring instrument used was Oral Hygiene Index-Simplified (OHIS-). Based on OHI-S, the oral hygiene can be categorized into poor within 3.0 - 6.0 score point, fair within $1.3-3.0$ score point, or good within $0.0-1.2$ score point. This study showed the oral hygiene index of depressed patients was 2.8 and categorized as fair.

Optimal oral hygiene behavior is required to maintain good oral hygiene. Mentally ill individuals might neglect optimal oral health behavior and are prone to a greater number of risk factors for oral and dental diseases than general population, therefore it is important for practitioners to educate the patients as we as their families regarding oral health importance, secondary side effects of their medications, and proper oral health behaviors.

\section{REFERENCES}

1. Lindert $J$, Bilsen $J$, Jakubauskiene $M$.
Public mental health. Eur J Public Health. 2017;27:32-5. DOI: 10.1093/eurpub/ckx163.

2. Lynda AO. The association between depression and self-perceived oral health in migrants of russian, somali and kurdish origin living in finland: A population based study. Semantic Scholar. 2017.

3. Ishtiaq M, Afridi MI, Imranullah, Khan SA. Depression: prevalence \& risk factors of depression among adult population of district peshawar. Prof Med J. 2018;25(08):1229-34. DOI: $10.29309 / \mathrm{TPMJ} / 18.4351$

4. Datta D, Kumar R, Narayanan A, Selvamary L, Sujatha. Depression and oral health. Int J Curr Res. 2018;10(3):66561-4.

5. Torales J, Barrios I, González I. Oral and Dental Health Issues in People with Mental Disorders. Medwave. 2017;17(08):e7045. DOI: 10.5867/ medwave.2017.08.7045.

6. Allen $C M$, Camisa $C$. The Challange of Oral Disease. FDI World Dental Federation. 2015. p. 13.

7. Buunk-Werkhoven YAB, Dijkstra A, Van der Wal $\mathrm{H}$, Basic N, Loomans SA, Van der Schans CP, et al. Promoting oral hygiene behavior in recruits in the dutch army. Mil Med. 2009;174(9):9716. DOI: $10.7205 /$ MILMED-D-05-0408.

8. Puspita NPV, Sirat SNM. Gambaran OHI-S dan perilaku menyikat gigi pada siswa kelas VI SDN 5 Pekutatan Kecamatan Pekutatan Kabupaten Jembrana Tahun 2016. J Skala Husada. 2017; 14(June 2014):1-21.

9. Narulita L, Diansari V, Sungkar S. Oral hygiene index simplified (OHI-S) pada murid kelas IV SD Negeri 24 Kuta Alam. J Caninus Dent 2016;1(4):6-8.

10. National Institute of Mental Health. Depression basics. National institutes of health. Science Writing, Press, and Dissemination Branch 2016. p. 7.

11. Fatima Z, Bey A, Azmi S, Gupta N, Khan A. Mental depression as a risk factor for periodontal disease: Acase-control study. Eur J Gen Dent. 2016;5(2):86-9. DOI: 10.4103/22789626.179557.

12. KumarA, KardkalA, DebnathS, Lakshminarayan J. Association of periodontal health indicators and major depressive disorder in hospital outpatients. J Indian Soc Periodontol. 2015 Sep-Oct;19(5):507-11. DOI: 10.4103/0972- 


\section{X.167161.}

13. Akcali A, Lang NP. Dental calculus: the calcified biofilm and its role in disease development. Periodontol 2000. 2018 Feb;76(1):109-15. DOI: $10.1111 / \mathrm{prd} .12151$.

14. Villa A, Connell CL, Abati S. Diagnosis and management of xerostomia and hyposalivation. Ther Clin Risk Manag. 2014;11:45-51. DOI: 10.2147/TCRM.S76282.

15. Kubbi J, Reddy L, Duggi L, Aitha H. Xerostomia: an overview. J Indian Acad Oral Med Radiol. 2015;27(1):85-9. DOI: 10.4103/09721363.167104

16. Nandaprasad, Sharma N, Reddy Y, Gowda M, Chaitanya BV, Nonitha $S$, et al. Assessment of oral hygiene, tooth brushing habits, and mucosal changes of non- institutionalized and institutionalized psychiatric patients in a tertiary rehabilitation ce. J Int Oral Heal. 2016;8(2):202-4.

17. Persson K, Axtelius B. Monitoring oral health and dental attendance in an outpatient psychiatric population. J Psychiatr Ment Health Nurs 2009 Apr;16(3):263-71.
18. Braimoh $\mathrm{OB}$, Soroye MO. Oral hygiene status of elderly population in port harcourt, rivers state, nigeria. African J Med Heal Sci. 2018;16(2):106-14. DOI: 10.4103/ajmhs. ajmhs 39_17.

19. Fitri AH, Tadjoedin FM, Soeroso Y. Distribusi penyakit periodontal berdasarkan kelompok usia di klinik periodonsia RSKGM FKG UI (Rekam Medik Periode 2004-2014). 2015.

20. Mushtaq R, Shoib S, Singh R, lqbal U, Shah $\mathrm{T}$, Mushtaq $\mathrm{S}$, et al. Is institutionalization a risk factor for poor oral health; a comparison of the oral status of schizophrenia and bipolar affective disorders. Int J Res Med Sci. 2014;2(2):580. DOI: 10.5455/2320-6012. ijrms20140540

21. Park SJ, Ko KD, Shin S II, Ha YJ, Kim GY, Kim HA. Association of oral health behaviors and status with depression: results from the korean national health and nutrition examination survey, 2010. J Public Health Dent. 2014;74(2):127-38. DOI: 10.1111/ jphd.12036. 